Tohoku J. exp. Med., 1981, 133, 257-266

\title{
The in Vitro Development of Immunoglobulin Producing Gells from the Human Bone Marrow Null Lymphocyte
}

\author{
Takeo Kuroyanagi and Kazuo Kura \\ The First Department of Internal Medicine, Saitama Medical \\ School, Moroyama-cho, Saitama-ken 350-04
}

\begin{abstract}
Kuroyanagi, T. and Kura, K. The in Vitro Development of Immunoglobulin Producing Cells from the Human Bone Marrow Null Lymphocyte. Tohoku J. exp. Med., 1981, 133 (3), 257-266 — The distribution of human bone marrow lymphocyte population was studied on twenty normal adults. The distribution of bone marrow lymphocytes were as follows: null lymphocytes $79.4 \%$, E-RFC $8.9 \%$, Thy ${ }^{+}$lymphocytes $0.4 \%, \mathrm{~T}_{\gamma} 0.9 \%, \mathrm{~T}_{\mu} 1.4 \%$, SmIg+ cells $7.8 \%$, EAC-RFC $11.7 \%$, EA-RFC $6.2 \%$, and $\mathrm{K}$ cells $2.7 \%$. Bone marrow null lymphocytes were intermediate in their size between small lymphocytes and lymphoblasts. The presence of a lot of short microvilli on null lymphocytes was demonstrated by scanning electron microscopic examinations. The bone marrow null lymphocytes had no cytoplasmic Ig. When the bone marrow null lymphocytes were mixedlymphocyte-cultured with allogeneic $\mathrm{T}$ lymphocytes and then stimulated with PWM, there developed Ig producing cells. Differences between pre-B cells and bone marrow null lymphocytes were discussed. human bone marrow lymphocyte population; bone marrow null lymphocyte; development of Ig producing cells; pre-B cell
\end{abstract}

The nature of the human bone marrow lymphocyte population remains still to be clarified. In mice the distribution of lymphocytes bearing mouse specific B lymphocyte antigen (MBLA), surface membrane immunoglobulin (SmIg), complement receptor and Fc receptor is $25 \sim 45 \%, 5 \sim 15 \%, 5 \sim 10 \%$ and $10 \sim 15 \%$, respectively (Greaves et al. 1973). A small portion of mice bone marrow lymphocytes is known to be $\mathrm{T}$ lymphocytes. According to Douglas (1976), more than $75 \%$ of human bone marrow lymphocytes are B lymphocytes and less than $25 \%$ are $\mathrm{T}$ lymphocytes.

However, little is known about the exact distribution of the human bone marrow lymphocytes population. The population of normal human bone marrow lymphocytes was determined and the morphology of bone marrow null lymphocytes was studied by transmission and scanning electron microscopy.

The in vitro development of Ig producing cells from the human bone marrow lymphocytes under the regulation of T lymphocytes by the PWM stimulation was also examined.

Received for publication, January 26, 1980. 


\section{Materials and Methods}

Twenty normal adults (12 males and 8 females) were examined.

Separation of lymphocytes from the normal human bone marrow aspirates

Three tenths to $0.5 \mathrm{ml}$ of the human bone marrow was aspirated from the sternum or iliac crest to a heparinized syringe. Bone marrow cells were suspended in $1 \mathrm{ml}$ of RPMI 1640 containing 10\% fetal calf serum (FCS) and 10\% ACD. The bone marrow cell suspension was filtered through aseptic gauzes to remove fatty tissues. The bone marrow cells were washed twice in the above RPMI 1640 solution and resuspended in $1 \mathrm{ml}$ of RPMI 1640 containing $10 \%$ FCS.

Three tenths $\mathrm{ml}$ of the bovine serum albumin (BSA) solutions in 10\% EDTA saline (pH 7.2), whose specific gravity is $1072,1068,1063,1059$ and 1045 , respectively, were put in sequence in a $6 \times 70 \mathrm{~mm}$ test tube. The above bone marrow cell suspension was overlayed on the BSA solution and centrifuged for $15 \mathrm{~min}$ at $2,700 \times \mathrm{g}$. Fractionated cells from centrifuges were stained with Giemsa stain and peroxidase stain to determine their morphologic characteristics (Peterson and Evans 1967).

\section{Immunofluorescence}

The viable bone marrow lymphocytes were stained with FITC labeled anti-light chain ( $k$ and $\lambda$ ) antibodies to determine the surface immunoglobulin ( $\mathrm{SmIg}$ ) bearing lymphocytes (Frøland and Natvig 1972).

\section{$E$ and $E A C$ rosette forming lymphocytes}

One tenth $\mathrm{ml}$ of lymphocyte suspension $\left(1 \times 10^{6} / \mathrm{mm}^{3}\right)$ was $\operatorname{mixed}$ with $0.1 \mathrm{ml}$ of $1 \%$ neuramidase-treated sheep erythrocytes (E) suspension or $0.1 \mathrm{ml}$ of $1 \%$ suspension of sheep erythrocytes coated with anti-E IgM antibodies and guinea pig complement (EAC) and then the mixture was incubated for $2 \mathrm{hr}$ at $4^{\circ} \mathrm{C}$. Then the percent of $\mathrm{E}$ or EAC rosette forming lymphocytes was calculated (Yata and Tachibana 1975).

\section{Fc receptor bearing lymphocytes}

Ox erythrocytes (Eox) sensitized with anti-Eox IgG antibodies (Eox A) were used to detect Fc receptor bearing lymphocytes. One tenth $\mathrm{ml}$ of lymphocyte suspension $\left(1 \times 10^{6} /\right.$ $\mathrm{mm}^{3}$ ) was mixed with $0.1 \mathrm{ml}$ of $1 \%$ Eox A suspension and Eox A rosette forming cells were calculated (van Oers et al. 1977).

$F c$ receptor positive $T$ cells

One tenth $\mathrm{ml}$ of lymphocyte preparation $\left(1 \times 10^{6} / \mathrm{mm}^{3}\right)$ was mixed with $0.1 \mathrm{ml}$ of $1 \% \mathrm{E}$ suspension and $0.1 \mathrm{ml}$ of $1 \%$ suspension of Eox sensitized with anti-Eox IgG antibodies (Eox $\mathrm{A}_{\gamma}$ ) or anti-Eox $\operatorname{IgM}$ antibodies (Eox $\mathrm{A}_{\beta}$ ).

The $\mathrm{E}$ and Eox $\mathrm{A}_{\gamma}$ double rosette forming cells were considered as $\mathrm{Fc}(\gamma)$ receptor positive $\mathbf{T}$ cells $\left(\mathrm{T}_{\gamma}\right)$. The $\mathbf{E}$ and Eox $\mathrm{A}_{\gamma}$ double rosette forming cells were considered as $\mathrm{Fc}(\mu)$ receptor positive $\mathrm{T}$ cells $\left(\mathrm{T}_{\mu}\right)$ (Moretta et al. 1975; Ferrarini et al. 1976).

$K$ cells

One tenth $\mathrm{ml}$ of lymphocyte suspension in $0.3 \%$ agar $\left(10^{5} / \mathrm{mm}^{3}\right)$ was put on the $2 \%$ EA suspension in $0.5 \%$ agar plate in a plastic petri dish $(35 \times 10 \mathrm{~mm})$. After 12 to $18 \mathrm{hr}$ incubation at $37^{\circ} \mathrm{C}$, the numbers of hemolytic plaques were calculated.

Thymus antigen bearing lymphocytes

Anti-thymus antigen serum was prepared by injecting human fetal thymus cells with complete Freund's adjuvant into rabbits. Anti-serum was thoroughly adsorbed with human serum and human blood lymphocytes removed of $\mathrm{E}$ rosette forming cells. The above adsorbed anti-serum was fractionated to obtain anti-thymus IgG.

The microcytotoxicity test using the above anti-Thy ${ }^{+}$IgG and guinea pig serum was carried out to determine $\mathrm{Thy}^{+}$lymphocytes.

Ig production of bone marrow null lymphocytes

Separation of bone marrow null lymphocytes. One $\mathrm{ml}$ of suspension of fractionated bone marrow lymphocytes in RPMI 1640 containing $10 \%$ FCS $\left(10^{7} / \mathrm{mm}^{3}\right)$ was mixed with $1 \mathrm{ml}$ of $1 \% \mathrm{E}$ saline suspension and $1 \mathrm{ml}$ of $1 \% \mathrm{EAC}$ saline suspension and incubated 
at $4^{\circ} \mathrm{C}$ for $2 \mathrm{hr}$. Then, the mixture was put on the Hypaque-Ficol solution and then centrifuged for $30 \mathrm{~min}$ at $500 \times \mathrm{g}$ to remove $\mathrm{E}$ and $\mathrm{EAC}$ forming cells. Bone marrow null lymphocytes were obtained from the interlayer between Hypaque-Ficol and suspension medium (Sakane and Green 1977).

Separation of $T$ cells from peripheral blood. Lymphocytes rich fractions were collected from blood by the Hypaque-Ficol method. Monocytes were removed from the above lymphocytes rich fractions by carbonyl-iron treatment.

The above lymphocytes were suspended in RPMI 1640 containing $10 \%$ FCS. Five tenths $\mathrm{ml}$ of the lymphocyte suspensions $\left(10^{7} / \mathrm{mm}^{3}\right)$ were mixed with the equal volume of $1 \%$ EAC suspensions. The mixture was incubated $3 \mathrm{hr}$ at $4^{\circ} \mathrm{C}$. Then, the mixture was put on the Hypaque-Ficol solution and contrifuged for $30 \mathrm{~min}$ at $500 \times \mathrm{g}$. Lymphocytes collected from the interlayer between Hypaque-Ficol and suspension medium were used as $\mathrm{T}$ cells rich fraction (Sakane and Green 1977).

The development of Ig producing cells from bone marrow null lymphocytes by the PWM stimulation. One tenth $\mathrm{ml}$ of bone marrow null lymphocyte suspension $\left(10^{5} / \mathrm{mm}^{3}\right)$ in RPMI 1640 containing $10 \%$ FCS was mixed with $0.1 \mathrm{ml}$ of allogeneic normal blood Tymphocyte suspensions $\left(10^{5} / \mathrm{mm}^{3}\right)$ in RPMI 1640 containing $10 \%$ FCS. And then the mixture was cultured in the $5 \% \mathrm{CO}_{2}$ incubator for 7 days at $37^{\circ} \mathrm{C}$. After 7 days' culture, PWM (10 g/ml) was added to the medium and the mixture was incubated for 4 days at $37^{\circ} \mathrm{C}$ in the $5 \%$ $\mathrm{CO}_{2}$ incubator.

After the culture, smears of lymphocytes were stained by FITC labeled anti-human gammaglobulin antibodies. The intracytoplasmic Ig bearing cells were determined by fluorescence microscopy.

\section{Results}

\section{The bone marrow cell fractionation}

Bone marrow cells were fractionated into seven fractions, as shown in Fig. 1.

The fraction I consisted mainly of platelets and megakaryocytes. The fraction II contained immature granulocytes. The fraction III consisted mainly of erythroblasts. Cells of fraction IV were monocytoid.

Eighty-five per cent of cells from the fraction $\mathrm{V}$ were bone marrow lymphocytes.

Fig. 1. Fractionation of bone marrow cells. Fraction I, platelets and megakaryocytes; II, immature granulocytes; III, erythroblasts; IV, monocytoid cells; V, lymphocytes and a few mature granulocytes; VI, mature granulocytes and a few lymphocytes; VII, red blood cells.

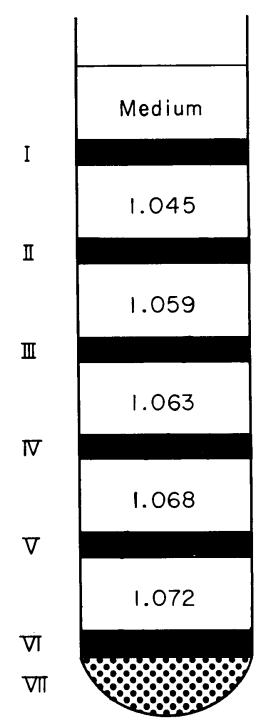


The fraction $\mathrm{V}$ contained a few mature granulocytes and reticulocytes. The fraction VI consisted of many mature granulocytes and a few lymphocytes.

Erythrocytes were present in the fraction VII.

A mixture of the fractions V and VI was put on the Hypaque-Ficol solution and then centrifuged for $10 \mathrm{~min}$ at $700 \times \mathrm{g}$ to obtain lymphocytes. The lymphocytes were present in the interlayer between Hypaque-Ficol and medium.

\section{Lymphocytes population of normal human bone marrow}

As shown in Table 1 and Fig. 2, E-RFC, thymus antigen positive $\left(\mathrm{Thy}^{+}\right)$ lymphocytes, $\mathrm{T}_{\gamma}, \mathrm{T}_{\mu}$, SmIg lymphocytes, EAC-RFC, EA-RFC and $\mathrm{K}$ cells

TABLE 1. Lymphocytes population of normal human blood and normal human bone marrow

\begin{tabular}{lcc}
\hline & \multicolumn{2}{c}{ Percentage } \\
\hline E-RFC & Blood & Bone marrow \\
Thy $^{+}$ & $66.4 \pm 11.4$ & $8.9 \pm 4.4$ \\
$\mathrm{~T}_{y}$ & $59.6 \pm 16.2$ & $0.4 \pm 0.3$ \\
$\mathrm{~T}_{\mu}$ & $14.2 \pm 6.6$ & $0.9 \pm 0.5$ \\
SmIg $^{+}$ & $21.2 \pm 8.9$ & $1.4 \pm 0.4$ \\
EAC-RFC & $17.2 \pm 5.3$ & $7.8 \pm 3.6$ \\
EA-RFC & $26.4 \pm 11.4$ & $11.7 \pm 9.8$ \\
K cells & $24.4 \pm 7.9$ & $6.2 \pm 3.3$ \\
\hline
\end{tabular}

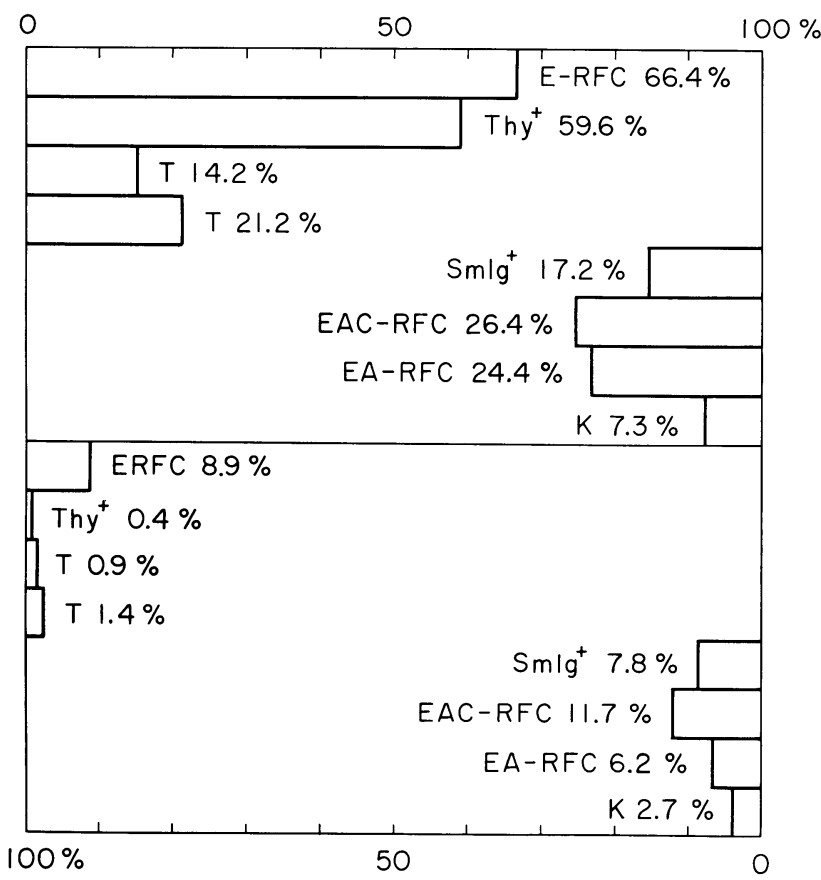

Fig. 2. Blood and bone marrow lymphocytes population. 
averaged $66.4 \pm 11.4 \%, 59.6 \pm 16.2 \%, 14.2 \pm 6.6 \%, 21.2 \pm 8.9 \%, 17.2 \pm 5.3 \%, 26.4 \pm$ $11.4 \%, 24.4 \pm 7.9 \%$ and $7.3 \pm 4.4 \%$, respectively, in normal human blood.

The population of normal human bone marrow lymphocytes averaged as follows: E-RFC $8.9 \pm 4.4 \%$, Thy lymphocytes $0.4 \pm 0.3 \%, \mathrm{~T}_{\gamma} 0.9 \pm 0.5 \%, \mathrm{~T}_{\mu} 1.4 \pm$ $0.4 \%$, SmIg ${ }^{+}$lymphocytes $7.8 \pm 3.6 \%$, EAC-RFC $11.7 \pm 9.8 \%$, EA-RFC $6.2 \pm 3.3 \%$ and $\mathrm{K}$ cells $2.7 \pm 1.8 \%$.

Null lymphocytes averaged $7.2 \%$ in the blood and $79.4 \%$ in the bone marrow lymphocytes.

\section{The morphology of the bone marrow null lymphocytes}

Null lymphocytes were intermediate in size between small lymphocytes and lymphoblasts. They had a larger nucleus than small lymphocytes and their chromatin was more leptochromatic. Usually their nucleus had no nucleolus. Their cytoplasm was more basophilic and a little more extensive than that of small lymphocytes and usually extended all around the nucleus.

The scanning electron microscopic examinations of bone marrow null cells revealed the presence of a lot of short microvilli, as shown in Fig. 3. The central dense bodies and a few ribosomes were demonstrated in the bone marrow null cells by transmission electron microscopic examinations (Fig. 4). The PAS staining of bone marrow null cells demonstrated the presence of coarse granules around the nucleus. The acid phosphatase staining of the bone marrow null cells showed focal coarse granules near the nucleus.

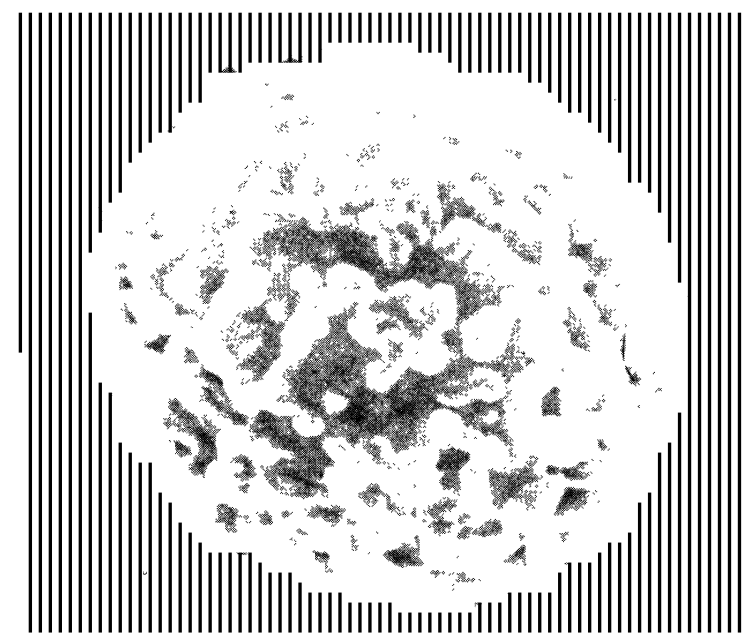

Fig. 3. Scanning electron microscopic picture of the human bone marrow null lymphocyte.

\section{The development of Ig producing cells from bone marrow null lymphocytes}

When normal bone marrow null lymphocytes were cultured with allogeneic normal $\mathrm{T}$ lymphocytes and then stimulated by PWM, there appeared intracytoplasmic Ig positive cells (Table 2). 


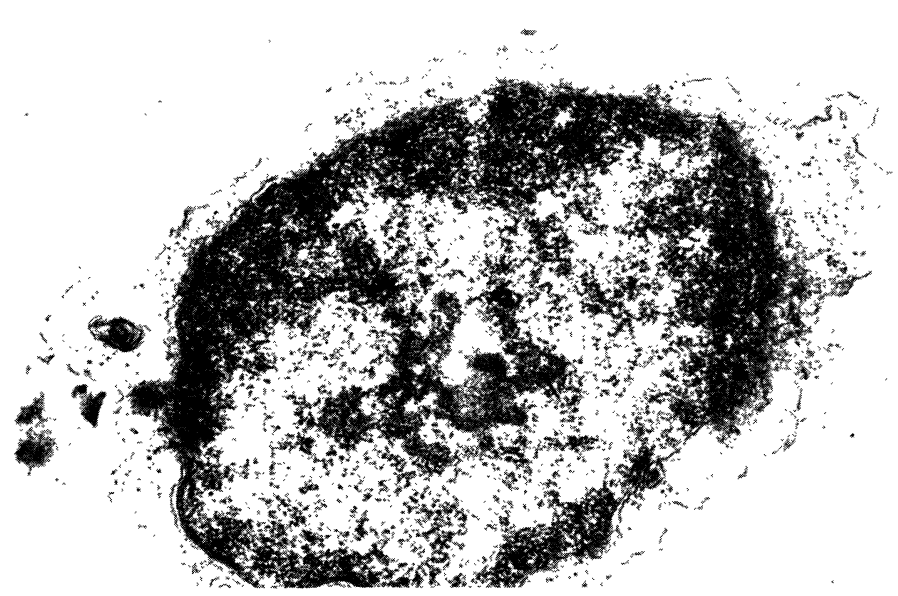

Fig. 4. Electron microscopic picture of the human bone marrow null lymphocyte.

TABLE 2. The percent of cytoplasmic Ig positive cells in the PWM-stimulated mixed lymphocyte culture of human normal bone marrow null lymphocytes

\begin{tabular}{lc}
\hline & $\%$ of $\mathrm{cIg}^{+}$cells \\
\hline $\begin{array}{c}\text { Normal BM null lymphocytes } \\
+\end{array}$ & $10.3 \pm 4.4$ \\
Normal blood T lymphocytes & \\
Normal BM null lymphocytes \\
+
\end{tabular} $\begin{gathered}\text { Blood T lymphocytes from patient } \\
\text { receiving SH }\end{gathered}$

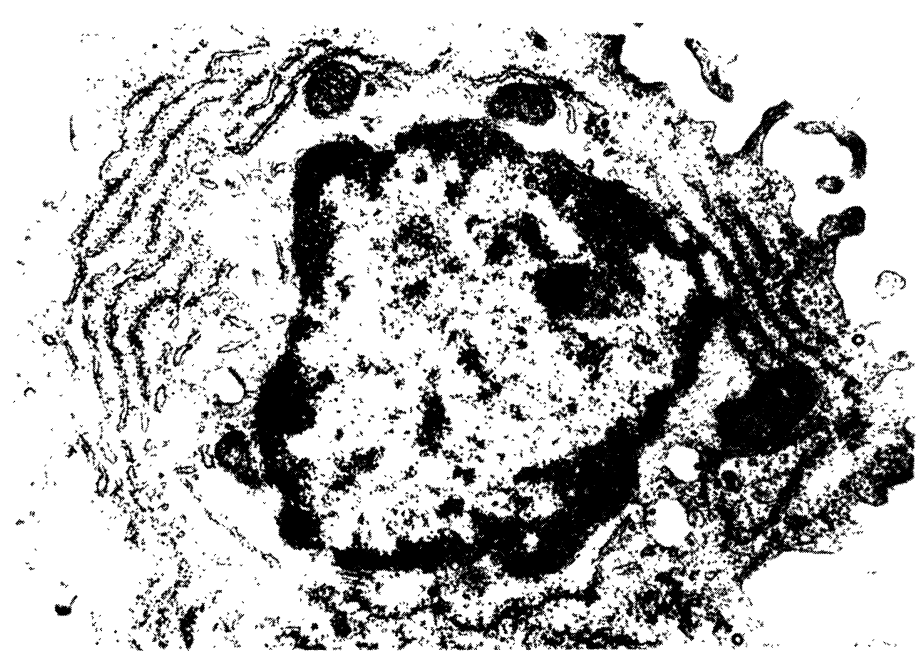

Fig. 5. Ig producing cells developed from the bone marrow lymphocytes. 
These cells had well developed endoplasmic reticulum, as shown in Fig. 5. The percent of these cells was $10.3 \pm 4.4 \%$.

When normal bone marrow null cells were mixed-lymphocyte-cultured with allogeneic $\mathrm{T}$ cells from patients receiving long-term steroid administration and then stimulated by PWM, the percent of intracytoplasmic Ig positive cells was markedly increased, averaging $24.1 \pm 9.3 \%$.

\section{Comment}

The rodent bone marrow contains a high percentage of cells resembling the small lymphocytes. It has been shown that these cells have a short life in the bone marrow (Elves 1972). There are few long-lived lymphocytes in the rodent bone marrow (Haas et al. 1971). Morphologically there are little differences among the bone marrow lymphocytes in rodents as well as in the human.

Little is known at present on the human bone marrow lymphocytes. One of the most important questions requiring an answer is "Are the bone marrow lymphocytes heterogeneous as those in the thoracic duct, the lymphnodes, the spleen and the peripheral blood?"

Our present studies indicate that the bone marrw lymphocytes are heterogeneous. The large portion of the bone marrow lymphocytes are the null lymphocytes, averaging $79.4 \%$. The bone marrow null lymphocytes are intermediate in their size between the small lymphocytes and the lymphoblasts. Their nuclear chromatin is leptochromatic. Usually their nucleus has no nucleolus. Their cytoplasma is more basophilic and a little more extensive than that of the small lymphocytes and usually extends all around the nucleus. They resemble the lymphocyte-transitional group of cells (Yoffey and Courtice 1970). Scanning electron microscopic examinations demonstrated the presence of a lot of short microvilli on their surface membrane. They have a few ribosomes and central bodies. The bone marrow null lymphocytes demonstrated focal coarse granules near the nucleus. They have no cytoplasmic Ig demonstrated by the immunofluorescence.

The human bone marrow lymphocytes contain not only B lymphocytes having $\mathrm{SmIg}^{+}$and complement receptors but $\mathrm{T}$ lymphocyte (E-RFC 8.9\%, Thy ${ }^{+} 0.4 \%$, $\mathrm{T}_{\gamma} 1.4 \%$ and $\mathrm{T}_{\mu} 0.9 \%$ ). It has been believed that there are no $\theta$ antigen positive lymphocytes in mice (Raff and Owen 1971). The present studies have demonstrated that there are few Thy antigen positive $\mathrm{T}$ lymphocytes. The presence of $\mathrm{T}$ lymphocytes in the human bone marrow is not due to the contamination of sinus blood, because there is a marked discrepancy between the distribution of $\mathrm{T}$ lymphocytes subclasses in the bone marrow and the peripheral blood, as shown in Fig. 2.

The human bone marrow lymphocytes contain a few B lymphocytes. The $\mathrm{SmIg}^{+}$lymphocytes average $7.8 \%$ and $\mathrm{B}$ lymphocytes having complement receptors $6.2 \%$. They also contain $\mathrm{K}$ cells, averaging $1.7 \%$.

Although the term B lymphocyte has commonly been interpreted as a 
reference to the bone marrow lymphocytes, a site of its origin has not been definitely established in man. Raff (1978) has shown that the development of B lymphocytes takes place in the microenvironment of the bone marrow in mammals.

It has been shown that the mouse bone marrow lymphocytes contain only a few $(5 \sim 15 \%)$ B lymphocytes having SmIg and complement receptors, in spite of the presence of a relatively large number $(25 \sim 45 \%)$ of mouse specific B lymphocyte antigen (MBLA) positive lymphocytes. These MBLA positive lymphocytes have no SmIg nor complement receptors (Greaves et al. 1973).

Basten et al. (1971), using a radiolabeled antigen suicide technique, whereby lymphocytes binding antigens are killed, have shown that, under the condition in which $\mathrm{T}$ and $\mathrm{B}$ lymphocytes are killed, bone marrow lymphocytes are unaffected. These results suggest that the bone marrow MBLA positive lymphocytes are too few in number to bind enough of this particular radiolabeled antigens or no receptors. The maturation to the $B$ lymphocyte having antigen receptor seems likely to take place after MBLA positive lymphocytes have migrated from the bone marrow. Whether or not the human bone marrow null lymphocytes are equivalent to the MBLA positive lymphocytes in mice requires further investigations.

Whether the bone marrow B lymphocytes are formed in the bone marrow or arrive there by the migration from other lymphoid organs has not been definitely established.

In mammals, B lymphocytes are generated first in the fetal liver and later in the bone marrow as it becomes hematopoietic (Osmond and Nossal 1974; Ryser and Vassalli 1974; Owen et al. 1975). Recent studies in mice, rabbits and humans have shown that the ontogenic appearance of B lymphocytes that bear surface IgM $\left(\mathrm{SmIgM}^{+}\right)$is preceded by the development of the large and small lymphoid cells, called pre- cells, which contain cytoplasmic IgM (cIgM), but lack SmIgM detected by the immunofluorescence; they are presumed to be the direct precursors of the B lymphocytes (LaFleur et al. 1972; Raff et al. 1976; Vogler et al. 1976; Lawton and Cooper 1977; Hayward et al. 1977; Gathings et al. 1977). Pre-B cells are found primarily in the bone marrow of adult mice and rabbits.

Although the direct generation of $\mathrm{SmIgM}^{+}$lymphocytes from radiolabeled cIgM+ SmIgM- cells has not yet been convincingly demonstrated in vitro, there is compelling evidence that pre-B cells are, in fact, the intermediate precursor cells of B lymphocytes. Pre-B cells appear in the liver and later in the bone marrow; during normal ontogeny they consistently precede the appearance of SmIgM+B lymphocytes. Large pre-B cells rapidly divide and give rise to small pre-B cells in vitro. It has been demonstrated in adult mice that B lymphocytes are derived from a pool of large, rapidly dividing $\mathrm{SmIg}^{-}$cells in the bone marrow.

Pearl et al. (1978) have shown that cIgM+ SmIgM- pre-B cells comprised $5.8 \pm$ $5.7 \%$ of lymphoid cells in the normal human bone marrow and that patients with infantile $\mathrm{x}$-linked agammaglobulinemia lacked $\mathrm{B}$ lymphocytes but had a normal frequency $(3.8 \pm 3.6 \%)$ of marrow pre-B cells.

In the present studies we found no $\mathrm{cIg}^{+} \mathrm{SmIg}^{-}$cells in the separated bone 
marrow lymphocytes. However, null lymphocytes produced Ig when they were cultured with allogeneic T cells and then stimulated by PWM.

Studies on the development of antibody producing cells in experimental animals and humans have produced strong evidence that the primary generation of B lymphocytes occurs independently of the influences of exogenous antigens or of T cells (Klinmann and Press 1975; Lawton et al. 1975). In contrast, the terminal differentiation of B lymphocytes to antibody secreting plasma cells is clearly triggered by antigens and regulated to a great extent by helper and suppressor $\mathrm{T}$ cells (Roit 1977).

The facts that the cooperation of $\mathrm{T}$ cells is required for the differentiation of bone marrow null lymphocytes to antibody producing cells by the PWM stimulation and that null lymphocytes lack cIg suggest strongly that bone marrow null cells are not pre-B cells.

The fact that the appearance of $\mathrm{cIg}^{+}$cells is markedly increased during the mixed lymphocyte culture of bone marrow null cells and allogeneic $\mathrm{T}$ cells from patients receiving long-term steroid administration suggests that steroid decreases suppressor T cells.

\section{References}

1) Basten, A., Miller, J.F.A.P., Sprent, J. \& Pye, J. (1971) Specific inactivation of thymus derived (T) and non-thymus (B) lymphocytes by ${ }^{125} \mathrm{I}$ labelled antigens. Nature New Biol., 231, 104-107.

2) Douglas, S.D. (1976) Cells involved in immune responses. In: Basic and Clinical Immunology, edited by H.H. Fudenberg, D.P. Stittes, J.L. Caldwell \& J.V. Wells, Maruzen, Tokyo, p. 81.

3) Elves, M.M. (1972) The Lymphocytes. 2nd Ed., Lloyd Luke, London.

4) Ferrarini, M., Moretta, L., Mingari, M.C., Tonda, P. \& Pernis, B. (1976) Receptor for IgM on T lymphocytes: specificity for the pentameric Fc fragment. Europ. J. Immunol., 6, 520-528.

5) Frøland, S.S. \& Natvig, J.B. (1972) Surface-bound immunoglobulin on lymphocytes from normal and immunodeficient humans. Scand. J. Immunol., 1, 1-12.

6) Gathings, W.F., Lawton, A.R. \& Cooper, M.D. (1977) Immunofluorescent studies of the development of pre-B cells, B lymphocytes and immunoglobulin isotype diversity in human. Europ. J. Immunol., 7, 804-815.

7) Greaves, M.F., Owen, J.J.T. \& Raff, M.C. (1973) $T$ and $B$ Lymphocytes. Origin, Properties and Role in Immune Response, Exerpta Medica, Amsterdam, p. 77.

8) Haas, R.J., Bohne, F. \& Fliedner, T.M. (1971) Cytokinetic analysis of slowly proliferating bone marrow cells during recovery from radiation injury. Cell Tissue Kinet., 4, $31-40$.

9) Hayward, A.R., Simons, M., Lawton, R.R., Cooper, M.D. \& Mage, R.G. (1977) Pre-B and $\mathrm{B}$ cells in rabbits. Ontogeny and allelic exclusion. Fed. Proc., 36, 1295.

10) Klinmann, N.R. \& Press, J.L. (1975) Expression of specific clones during B cell development. Fed. Proc., 34, 47.

11) LaFleur, L., Miller, R.G. \& Phillips, R.A. (1972) A quantitative assay for progenitors of bone marrow-associated lymphocytes. J. exp. Med., 135, 1363-1374.

12) Lawton, A.R. \& Cooper, M.D. (1977) Two new stages of antigen independent B cell development in mice and humans. In: Development of Host Defenses, edited by M.D. Cooper \& D.H. Dayton, Raven Press, New York, p. 43.

13) Lawton, A.R., Kincade, P.W. \& Cooper, M.D. (1975) Sequential expression of germ line genes in development of immunoglobulin class diversity. Fed. Proc., 34, 33. 
14) Moretta, L., Ferrarini, M., Durante, M.L. \& Mingari, M.C. (1975) Expression of a receptor for IgM by human $\mathrm{T}$ cell in vitro. Europ. J. Immunol., 5, 565-573.

15) Osmond, D.G. \& Nossal, G.J.V. (1974) Differentiation of lymphocytes in the mouse bone marrow. 11. Kinetics of maturation and renewal of anti-globulin binding cells studied by double labeling. Cell. Immunol., 13, 132-142.

16) Owen, J.J.T., Raff, M.C. \& Cooper, M.D. (1975) Studies on the generation of B lymphocytes in the mouse embryo. Europ. J. Immunol., 5, 468-477.

17) Pearl, E.R., Vogler, L.B., Okas, A.J., Crist, W.M., Lawton, A.R. \& Cooper, M.D. (1978) B lymphocytes precursors in human bone marrow: An analysis of normal individuals and patients with antibody deficiency state. J. Immunol., 120, 1169-1178.

18) Peterson, E.A. \& Evans, W.H. (1967) Separation of bone marrow cells by sedimentation at unit gravity. Nature, 214, 824-878.

19) Raff, M.C. (1978) Development and modulation of B lymphocytes: Studies on newly formed B cells and their putative precursors in hematopoietic tissue in mice. In: Origin of Lymphocyte Diversity. Part I. Cold Spring Harbor Symposia on Quantative Biology, XLI, Tokyo University Press, Tokyo, p. 159.

20) Raff, M.C. \& Owen, J.J.T. (1971) Thymus derived lymphocytes: Their distribution and role in the development of peripheral lymphoid tissue of the mouse. Europ. J. Immunol., 1, 27-35.

21) Raff, M.C., Megson, M., Owen, J.J.T. \& Cooper, M.D. (1976) Early production of intracellular IgM by lymphocyte precursor in mice. Nature, 259, 224-226.

22) Roit, I.M. (1977) Essential Immunology. 3rd Ed., Blackmell Scientific Publications, Oxford, pp. 86-88.

23) Ryser, J.E. \& Vassalli, P. (1974) Mouse bone marrow lymphocytes and their distribution. J. Immunol., 113, 719-728.

24) Sakane, T. \& Green, I. (1977) Human suppressor T cells induced by concanavalin A: suppressor $\mathrm{T}$ cells belong to distinctive $\mathrm{T}$ cell subclass. J. Immunol., 119, 1169-1178.

25) van Oers, M.H.J., Zeijlemaker, W.P. \& Schellekens, P. Th. A. (1977) Separation and properties of EA-rosette-forming lymphocytes in humans. Europ. J. Immunol., 7, 143-150.

26) Vogler, L.B., Pearl, E.R., Gathings, W.E., Lawton, A.R. \& Cooper, M.D. (1976) B lymphocytes precursors in bone marrow in immunoglobulin deficiency diseases. Lancet, 2, 376-381.

27) Yata, J. \& Tachibana, T. (1975) Determination of human lymphocyte subpopulation, E-RFC and EAC-RFC. In: Jikken Meneki Sosaho A, edited by Nippon Meneki Gakkai, pp. 451-454. (Japanese)

28) Yoffey, J.M. \& Courtice, F.C. (1970) Lymphatics, Lymph and the Lymphmyeloid Complex, Academic Press, London-New York, pp. 646-670. 